\title{
Interplay between food and gut microbiota in health and disease
}

Danneskiold-Samsøe, Niels Banhos; de Freitas Queiroz Barros, Helena Dias; Santos, Rosangela; Bicas, Juliano Lemos; Cazarin, Cinthia Baú Betim; Madsen, Lise; Kristiansen, Karsten; Pastore, Glaucia Maria; Brix, Susanne; Junior, Mario Roberto Marostica

Published in:

Food Research International

Link to article, DOI:

10.1016/j.foodres.2018.07.043

Publication date:

2019

Document Version

Peer reviewed version

Link back to DTU Orbit

Citation (APA):

Danneskiold-Samsøe, N. B., de Freitas Queiroz Barros, H. D., Santos, R., Bicas, J. L., Cazarin, C. B. B.,

Madsen, L., Kristiansen, K., Pastore, G. M., Brix, S., \& Junior, M. R. M. (2019). Interplay between food and gut microbiota in health and disease. Food Research International, 115, 23-31.

https://doi.org/10.1016/j.foodres.2018.07.043

\section{General rights}

Copyright and moral rights for the publications made accessible in the public portal are retained by the authors and/or other copyright owners and it is a condition of accessing publications that users recognise and abide by the legal requirements associated with these rights.

- Users may download and print one copy of any publication from the public portal for the purpose of private study or research.

- You may not further distribute the material or use it for any profit-making activity or commercial gain

- You may freely distribute the URL identifying the publication in the public portal 


\section{Accepted Manuscript}

Interplay between food and gut microbiota in health and disease

Niels Banhos Danneskiold-Samsøe, Helena Dias de Freitas Queiroz Barros, Rosangela Santos, Juliano Lemos Bicas, Cinthia Baú Betim Cazarin, Lise Madsen, Karsten Kristiansen, Glaucia

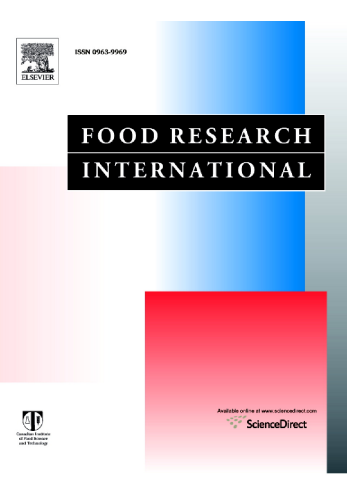
Maria Pastore, Susanne Brix, Mario Roberto Marostica Junior

PII: S0963-9969(18)30582-9

DOI: doi:10.1016/j.foodres.2018.07.043

Reference: FRIN 7783

To appear in: Food Research International

Received date: 15 April 2018

Revised date: 1 July 2018

Accepted date: 28 July 2018

Please cite this article as: Niels Banhos Danneskiold-Samsøe, Helena Dias de Freitas Queiroz Barros, Rosangela Santos, Juliano Lemos Bicas, Cinthia Baú Betim Cazarin, Lise Madsen, Karsten Kristiansen, Glaucia Maria Pastore, Susanne Brix, Mario Roberto Marostica Junior, Interplay between food and gut microbiota in health and disease. Frin (2018), doi:10.1016/j.foodres.2018.07.043

This is a PDF file of an unedited manuscript that has been accepted for publication. As a service to our customers we are providing this early version of the manuscript. The manuscript will undergo copyediting, typesetting, and review of the resulting proof before it is published in its final form. Please note that during the production process errors may be discovered which could affect the content, and all legal disclaimers that apply to the journal pertain. 


\title{
INTERPLAY BETWEEN FOOD AND GUT MICROBIOTA IN HEALTH AND DISEASE
}

\author{
Niels Banhos Danneskiold-Samsøe ${ }^{a, *}$, Helena Dias de Freitas Queiroz Barros ${ }^{b, *}$, Rosangela \\ Santos $^{c}$, Juliano Lemos Bicas ${ }^{c}$, Cinthia Baú Betim Cazarin ${ }^{b}$, Lise Madsen ${ }^{\text {a,d }}$, Karsten \\ Kristiansen $^{\mathrm{a}, \mathrm{e}, \#}$, Glaucia Maria Pastore ${ }^{\mathrm{c}}$, Susanne Brix ${ }^{\mathrm{f}}$, \\ Mario Roberto Marostica Junior ${ }^{\text {b,\# }}$
}

${ }^{\text {a} L a b o r a t o r y ~ o f ~ G e n o m i c s ~ a n d ~ M o l e c u l a r ~ B i o m e d i c i n e, ~ D e p a r t m e n t ~ o f ~ B i o l o g y, ~ U n i v e r s i t y ~ o f ~}$ Copenhagen, DK-2100 Copenhagen, Denmark

${ }^{\mathrm{b}}$ Department of Food and Nutrition, University of Campinas - UNICAMP, 13083-862 Campinas, SP, Brazil

${ }^{\mathrm{c}}$ Department of Food Science, University of Campinas - UNICAMP, 13083-862 Campinas, SP, Brazil

${ }^{\mathrm{d}}$ Institute of Marine Research (IMR), Postboks 1870, Nordnes, N-5817, Bergen, Norway

${ }^{\mathrm{e}}$ Institute of Metagenomics, BGI-Shenzhen, Shenzhen 518083, China

${ }^{\mathrm{f}}$ Department of Biotechnology and Biomedicine, Technical University of Denmark, DK-2800 Kgs. Lyngby, Denmark

*These authors contributed equally and are shared first authors

\#Corresponding authors

E-mail addresses for corresponding authors:

Karsten Kristiansen: kk@bio.ku.dk

Mario Roberto Marostica Junior: mmarosti@g.unicamp.br 


\section{ABSTRACT}

Numerous microorganisms colonize the human gastrointestinal tract playing pivotal roles in relation to digestion and absorption of dietary components. They biotransform food components and produce metabolites, which in combination with food components shape and modulate the host immune system and metabolic responses. Reciprocally, the diet modulates the composition and functional capacity of the gut microbiota, which subsequently influence host biochemical processes establishing a system of mutual interaction and inter-dependency. Macronutrients, fibers, as well as polyphenols and prebiotics are strong drivers shaping the composition of the gut microbiota. Especially, short-chain fatty acids produced from ingested fibers and tryptophan metabolites are key in modulating host immune responses. Since reciprocal interactions between diet, host, and microbiota are personal, understanding this complex network of interactions calls for novel use of large datasets and the implementation of machine learning algorithms and artificial intelligence. In this review, we aim to provide a base for future investigations of how interactions between food components and gut microbiota may influence or even determine human health and disease.

Keywords: gut microbiota; macronutrients; polyphenols; prebiotics; health; disease. 


\section{INTRODUCTION}

The complex microbial communities present in the intestinal tract play pivotal roles as modulators of metabolic responses, the immune system, and human health (Ventura, O'Toole, de Vos, \& van Sinderen, 2018). It is widely accepted that many aspects of human health are affected by the gut microbiota, although information regarding mechanisms of action is still missing (Ventura et al., 2018). In particular, studies addressing causality in relation to observed correlations are scarce (Surana \& Kasper, 2017). Nevertheless, numerous studies have corroborated the notion that the intestinal microbial communities play an important role in energy homeostasis and may thus modulate weight loss or gain and obesity-associated disorders (Rosenbaum, Knight, \& Leibel, 2015). The gut microbiota and bacterial metabolites have also been associated with regulation of blood pressure (Marques, Mackay, \& Kaye, 2018), chronic kidney disease (Sircana et al., 2018) and critical factors associated with cardiovascular disease. Additionally, alterations in gut microbial composition or function have been associated with age-related health impairment (Clark \& Walker, 2018; O'Toole \& Jeffery, 2018), changes in host immune status (Rooks \& Garrett, 2016), and thus, inflammatory bowel disease, allergy, and asthma (Carding, Verbeke, Vipond, Corfe, \& Owen, 2015).

Therefore, several studies have focused on how different factors can modulate the composition and function of the gut microbiota (Marchesi et al, 2016). Diet is currently considered as one of the most important modifiers (Graf et al., 2015). Macronutrients and micronutrients, as well as prebiotics, probiotics (Wang et al., 2015), food additives, and other minor components including contaminants can modulate the microbiota (Roca-Saavedra et al., 2018). The overall balance between the macronutrients protein, carbohydrate and fat is known to influence the composition and functional potential of the gut microbiota (reviewed in Madsen, Myrmel, Fjaere, Liaset, \& Kristiansen, 2017). Due to the compositional nature of a diet, it may therefore be difficult to clearly define the individual roles of each dietary component on the gut microbiota. The following subdivisions should be regarded in this light. The objective of this article is to review the most recent knowledge regarding effects of the main food components, encompassing carbohydrates, proteins, lipids, prebiotics, and polyphenols on the gut microbiota, and the health benefits on the host of metabolites derived from microbial biotransformation of these food components. 


\section{EFFECT OF CARBOHYDRATES ON MICROBIOTA}

Intake of complex carbohydrates, so-called fibers, is associated with beneficial effects in a wide range of conditions including obesity, inflammatory bowel disease, and asthma in both rodents and humans (Cazarin et al., 2016; Kovatcheva-Datchary et al., 2015; Trompette et al., 2014). While simple carbohydrates typically are completely absorbed in the small intestine, a large number of complex carbohydrates from the diet is not digested in the upper gastrointestinal tract, owing to their resistance towards the enzymatic activities of human digestive enzymes. Consequently, the complex, mostly non-starch and resistant starch, dietary polysaccharides pass through the small intestine and serve as substrates for the colonic microbiota. These compounds can be fermented by several gut bacterial species leading to the generation of metabolites such as short-chain fatty acids (SCFAs), $\mathrm{CO}_{2}$, and $\mathrm{H}_{2}$ that shape the intestinal environment (Chassard \& Lacroix, 2013).

The consumption of a plant-based diet, rich in fiber, correlates with an increased abundance of the genera Roseburia, Lachnospira and Prevotella as well as increased SCFA production (Figure 1) (De Filippis et al., 2015). Both changes in gut microbiota composition and metabolite abundances by intake of fiber may independently influence disease outcome. However, it is important to note that fiber may also impact the host through effects independent of the gut microbiota, for example through fecal bulking. Not all fibers are equal in terms of ability to modify gut microbiota composition and activity. First, not all types of fibers are converted by the microbiota, and only the microbiota accessible carbohydrates (MAC) will elicit the generation of the metabolites described above. Secondly, particular fiber types serve as substrates for certain bacteria, and some of the produced biotransformed products may be used as substrates for other bacteria in the community (Reviewed in Cockburn \& Koropatkin, 2016). As most members of the gut microbiota are biased towards metabolizing mono- and oligosaccharides, and bacteria differ in their carbohydrate processing capabilities, cross-feeding between bacteria is essential for optimal digestion of complex polysaccharides (Cockburn \& Koropatkin, 2016). In basic terms, crossfeeding between bacteria will overall lead to the development of individually-based bacterial community structures depending on the types of ingested fibers, and thus, a change in the intake of fiber types may elicit complex changes in the overall structure and function of the gut microbiota. Gut bacteria vary greatly in the number of polysaccharide degrading enzymes. While some bacteria are considered generalists and thus able to metabolize a wide array of carbohydrates, others are highly specialized. Many members of the Bacteroidetes phylum including Bacteroides thetaiotaomicron and Bacteroides intestinalis are putative generalists (El Kaoutari, Armougom, 
Gordon, Raoult, \& Henrissat, 2013). In contrast, other members of the gut microbiota, for example, Prevotella copri and Rosaburia intestinalis are putative specialists (El Kaoutari, Armougom, Gordon, Raoult, \& Henrissat, 2013). Thus, it is likely that effects of dietary carbohydrates on gut microbiota do not influence the different species equally. The fiber-related bacterial community dependency was nicely illustrated in a recent study (Reichardt et al., 2018). By incubating human feces with fifteen non-digestible carbohydrates it was demonstrated that not only the type of substrates offered to the microbiota, but also the interactions between the bacteria in the intestinal environment were important for the type of SCFAs being produced. Specifically, Eubacterium hallii utilized 1,2-propanediol produced from rhamnose by Blautia spp. (Reichardt et al., 2018). The authors suggested that the absence of some keystone species could decrease non-digestible carbohydrate fermentation. In addition, it was reported that the initial $\mathrm{pH}$ of the environment, by affecting the activity of transferases involved in butyrate formation, may control butyrate production (Reichardt et al., 2018). Another recent study illustrated how differential chain-length preferences in bacteria for capture and transport of xylosyl units facilitate bacterial co-growth on abundant dietary fibers such as xylan (Leth et al., 2018). Combined this illustrates the complexity related to understanding the role of fiber types in shaping the gut microbiota composition and SCFA production.

While functional fiber-microbiota interactions are still challenging to pinpoint in vivo, the extensive use of correlation analyses has shown clear connections between the amount of dietary fiber intake, the activity of different bacteria, and the formation of SCFAs in humans. A study by Duncan et al., (2007) provides an example of such connections. In this study, 19 healthy obese male volunteers received a diet low in carbohydrates/fibers. They observed changes in the gut microbiota comprising a decreased abundance of Roseburia spp, Eubacterium rectale and Bifidobacteria, concomitant with a decrease in the level of SCFAs in feces, and with the reduction in fiber intake correlating with decreased levels of butyrate in feces.

Changes in fiber intake may further have trans-generational effects regarding the shaping of the gut microbiota composition. As an example, Roytio, Mokkala, Vahlberg, \& Laitinen (2017) observed a positive correlation between fiber intake and the diversity and richness of the microbiota in overweight pregnant women. Such changes may persist for generations as Sonnenburg et al. (2016) observed that low intake of MAC decreased the diversity of the microbiota, and this decrease persisted through four generations of mice, and was not reversible even after increasing MAC intake in the offspring. Given the effect of maternal environmental factors on offspring, these 
data are relevant to understanding the impact of the transition to a Western diet, typically low in dietary fiber, in relation to the long-term incidence of a number of non-communicable diseases.

\section{EFFECT OF PREBIOTICS ON MICROBIOTA}

Dietary prebiotics are defined as substrates that are selectively utilized by host microorganisms conferring a health benefit (Gibson et al., 2017). They typically consist of nondigestible carbohydrates although the concept of prebiotics has expanded to include a broader array of compounds (Gibson et al., 2017). Prebiotics consisting of oligosaccharides are common ingredients in nutritional supplements designed for clinical management of disease states, but solid documentation proving their benefits to intestinal morphology and function is scarce. Studies have emphasized the importance of the relationship between prebiotics and the gut microbiota. One of the functional effects of prebiotics has been related to an increase of the abundance of Bifidobacterium and Lactobacillus species given their ability to aid digestion, reduce constipation, resist infections, prevent traveler's diarrhea, and ameliorate inflammatory bowel disease (Figure 1) (reviewed in Gibson et al., 2010). Other effects have been reported in relation to prebiotics, gut microbiota composition, and lactose intolerance. In a randomized trial, Azcarate-Peril et al. (2017) tested the impact of highly purified (>95\%) galactooligosaccharides (GOS) on the colonic bacteria in humans with self-reported dairy intolerance. In response to GOS, the authors found an increase in the relative abundance of Bifidobacterium, Faecalibacterium, and Lactobacillus (Figure 1). Introduction of dairy products into the diet increased the abundance of Roseburia species 36 to 66 days after the intervention, which correlated with improvements in lactose tolerance. These results suggest that lactose-metabolizing bacteria interact with GOS to improve tolerance to dairy products. Of note, prebiotics may result in localized activity in sub-compartments of the colon. Using a Simulator of the Human Intestinal Microbial Ecosystem, Daguet et al. (2016) showed that fructooligosaccharides (FOS) and arabinogalactan increased SCFA synthesis in different areas of the colon (proximal colon for FOS, and distal colon for arabinogalactan fermentation).

The gut barrier refers to the intestinal cells and mucus layer that under normal conditions constitute an impenetrable barrier against host exposure to large luminal molecules. A decrease in gut barrier function may lead to intestinal inflammation and the influx of larger luminal molecules such as lipopolysaccharides associated with detrimental effects on the host (reviewed in Ramanan \& Cadwell, 2016; Winer, Luck, Tsai, \& Winer, 2016). By inoculating co-cultures of enterocytes, such as Caco-2 cells, and monocytes (THP1) with filtered simulator suspensions, Daguet et al. 
(2016) showed that compartment-specific metabolites might lead to differential effects in relation to gut barrier function.

There is also evidence that addition to infant formula of FOS and GOS, which are different from oligosaccharides present in human milk, results in softening of the fecal bolus, decreased stool $\mathrm{pH}$, increased luminal osmotic water binding capacity and fecal SCFA level as compared to nonprebiotics added formula (reviewed in Vandenplas, Zakharova, \& Dmitrieva, 2015). Prebiotic supplementation may also hold potentials in older children. In a randomized trial, the effects of GOS ingestion were tested in pediatric patients (4-16 years of age) with chronic constipation. This study demonstrated that administration of 1.7 gram of GOS per day increased bowel movement frequency, relieved straining during defecation, and decreased stool consistency in comparison with the placebo group receiving maltodextrin (Beleli, Antonio, dos Santos, Pastore, \& Lomazi, 2015).

It is important to note that prebiotics may not only exert their effects by modifying abundance or activity of microbes. A novel mechanism based on specific and direct prebiotic interactions using inulin and short-chain FOS demonstrated improved ability to maintain epithelial barrier function and to protect from injury caused by the non-invasive pathogen enterohemorrhagic E. coli $\mathrm{O} 157: \mathrm{H} 7$ (EHEC) despite the absence of other microbes (Wu et al., 2017). GOS may also inhibit adherence of E. coli to enterocytes (Shoaf, Mulvey, Armstrong, \& Hutkins, 2006). These results suggest that prebiotics may improve gut barrier function, and may be relevant for specific consumer groups during certain phases of life.

\section{EFFECT OF PROTEINS ON MICROBIOTA}

Studies focusing on protein intake have pinpointed how consumption of a Western diet rich in meat, which is typically high in animal-based protein, is reflected in the composition and functional potential of gut bacterial communities in humans (Wu et al., 2011). The general influence of animal protein intake on the gut microbiota composition is also demonstrated by the difference in microbiota compositions of carnivores and herbivores (Muegge et al., 2011). Intake of animal-based protein has been associated with an increased risk for development of atherosclerosis. This is envisaged to be dependent on transformation of L-carnitine and phosphatidylcholine, present in red meats and egg (Koeth et al., 2013; Tang et al., 2013). These compounds are converted into trimethylamine by the gut microbiota and subsequently transformed into trimethylamine oxide (TMAO) in the liver, leading to elevated levels of TMAO in circulation (Koeth et al., 2013; Tang et al., 2013). High level of TMAO in the circulation was also recently linked to obesity development 
(Dumas et al., 2017). While the data linking TMAO to atherosclerosis seem convincing, the fact that intake of fish, known to protect against cardiovascular diseases, also leads to elevated levels of TMAO in circulation has raised skepticism concerning the link between TMAO and cardiovascular disease (Cho et al., 2017; Landfald, Valeur, Berstad, \& Raa, 2017). However, in a recent study focusing of the gut microbiota of 218 individuals with atherosclerosis, it was found that the potential for TMA production in bacteria was a common denominator (Jie et al., 2017), hence pointing to continuous supply of TMA from the bacterial pool as a possible disease contributor (Figure 1).

In contrast to intake of animal protein, intake of plant protein appears to induce positive effects on metabolism and intestinal homeostasis. Thus, a large prospective cohort study showed that intake of plant protein was associated with a moderately decreased risk of type 2 diabetes (Malik, Li, Tobias, Pan, \& Hu, 2016). A meta-analysis including 13 randomized controlled trials also showed improved glycemic control, as measured by lowered HbA1c, by replacing animal with plant protein (Viguiliouk et al, 2015). Rodent studies have corroborated results in humans. Mice fed a high-fat/high-protein diet based on soy gained less weight than mice fed diets based on cod, beef, chicken and pork, but still, mice fed the soy-based diet gained more weight than mice fed a diet based on casein (Liisberg et al., 2016). By contrast, rats fed a high-fat diet based on soy protein gained less weight and displayed lower body fat content compared to rats fed a high-fat diet based on casein (Torre-Villalvazo, Tovar, Ramos-Barragan, Cerbon-Cervantes, \& Torres, 2008). These results could involve changes in the gut microbiota as rats fed soy protein showed lower levels of Lactobacillus compared to rats fed meat proteins (Zhu et al., 2015). The results revealed a tighter microbiota clustering of rats fed the non-meat proteins casein and soy, again indicating compositional and functional differences between rats fed diets based on meat proteins and nonmeat proteins (Zhu et al, 2015). A follow-up study showed that young rats fed a diet with proteins from chicken $(17.7 \%$ ) for 14 days exhibited an increase in the relative abundance of the genus Lactobacillus, whereas the opposite pattern was observed in middle-aged rats (Zhu et al., 2017).

Mouse studies have shown that proteins from seafood as constituents of a Western diet are less obesogenic than proteins from terrestrial animals. This difference in obesity development was associated with changes in the relative abundance of Bacteroidales and Clostridiales (Figure 1), accompanied with changes in the abundance of genes involved in metabolism of aromatic amino acids in the microbiomes of mice fed the seafood-based Western diet (Holm et al., 2016). In comparison to terrestrial protein sources, seafood protein contains high levels of taurine (Spitze, 
Wong, Rogers, \& Fascetti, 2003). Addition of taurine to the diet or drinking water has been demonstrated to prevent diet-induced obesity and steatosis in rodents (Chang et al., 2011; Nakaya et al., 2000; Nardelli et al., 2011). In mice, taurine supplementation reduced the abundance of Proteobacteria, especially Helicobacter and resulted in increased SCFA content in feces (Yu, Guo, Shen, \& Shan, 2016), changes that would be expected to improve gut health.

Protein sources from milk (casein and whey protein) have also been reported to convey antiobesogenic effects in mouse models on high-fat diets (Liisberg et al., 2016; Lillefosse et al., 2014; McAllan, Speakman, Cryan, \& Nilaweera, 2015; Tranberg, Madsen, Hansen, \& Hellgren, 2015). The actions of casein and whey-based feed have been related to the high content of the branchedchain amino acids (BCAAs) valine, leucine, and isoleucine. Interestingly, supplementation with dietary BCAAs in mice was reported to delay age-dependent changes in the gut microbiota (Yang et al., 2016) and to increase the abundance of Akkermansia and Bifidobacterium in the gut. High levels of A. muciniphilia (Everard et al., 2013; Shin et al., 2014) and some strains of Bifidobacteria (An et al., 2011; Z. Li, Jin, Oh, \& Ji, 2016; Wang et al., 2015) have been reported to protect against dietinduced obesity. Intake of a whey protein isolate has also been reported to specifically increase the abundance of Lactobacillaceae/Lactobacillus (Figure 1) and decrease the abundance of Clostridiaceae/Clostridium (McAllan et al., 2015), and in comparison to casein, whey protein intake was reported to increase the levels of Lactobacilli and Bifidobacteria in a rat model of colitis (Sprong, Schonewille, \& van der Meer, 2010). Several species of Lactobacilli have been reported to reduce adiposity in mice and be associated with weight-loss in humans (Park et al., 2013; Yoo et al, 2013; Isokpehi, Simmons, Johnson, \& Payton, 2017) suggesting that protein-associated changes in the gut microbiota might be causally linked with improved metabolic function. However, it remains to be established whether such changes in the composition of the gut microbiota are causally related to the anti-obesogenic actions of specific proteins such as milk and plant proteins.

\section{EFFECT OF LIPIDS ON THE MICROBIOTA}

The gut microbiota plays a pivotal role in relation to many chronic disorders that are influenced by the type and level of dietary fat intake. One example is obesity, which has been associated with taxonomical changes in the gut microbiota, and where the changes may likely reflect differences in dietary fat levels or lipid types rather than obesity (Caesar, Tremaroli, Kovatcheva-Datchary, Cani, \& Backhed, 2015; Xiao et al., 2017; Yu et al., 2014). The amount of dietary fat in modern Western diets is comparable to a Paleolithic intake, but it is likely that the 
types of ingested lipids have undergone marked shifts during human evolution (Eaton, Eaton, Konner, \& Shostak, 1996). Changes in the type of dietary lipids may also play a role in eliciting the changes in microbiota composition seen in Westernized as compared to indigenous human cultures (De Filippo et al., 2010; Rampelli et al., 2015).

While it is well documented that differences in carbohydrate and protein consumption may drive changes in the composition of the gut microbiota (Holmes et al., 2017), the role of lipids is less well established. However, some lipids seem to elicit significant changes in the gut microbiota composition. Studies of conventionally raised and germ-free mice fed diets with lipids of different fatty acid composition show that the interaction between the dietary fat source and the gut microbiota impacts on weight gain, adipose tissue inflammation, and colitis (Caesar, Tremaroli, Kovatcheva-Datchary, Cani, \& Backhed, 2015; Devkota et al., 2012). Thus, transfer of microbiota from mice fed fish oil- versus lard-based diets into germ-free mice lowered weight gain and lardinduced inflammation (Caesar et al., 2015; Cazarin et al., 2015). Similarly, colitis only occurred in germ-free mice mono-colonized with Bilophila wadsworthia if the mice were fed a milk-fat based diet, whereas a safflower oil-based diet did not elicit a response (Devkota et al., 2012). In order to understand such interactions, it is imperative to understand how different lipids interact with our gut microbiota.

Few dietary intervention studies have focused exclusively on modulating the type of dietary fat source. Still, the dietary lipid origin has been shown to impact both on the composition and diversity of the cecal and colonic microbiota in rodents (Caesar et al., 2015; Huang et al., 2013; Li et al., 2017; Patterson et al., 2014; Robertson et al., 2017), driving associations in humans between certain bacterial taxa and different dietary fats (Wu et al., 2011). In the few studies conducted in rodents, the effect of fat source on bacterial taxa differs somewhat between studies. One study in mice fed a lard-containing diet reported an increase in the abundance of Bacteroides, Turicibactor, and Bilophila, while mice consuming a fish oil-based diet were enriched for Bifidobacterium, Adlercreutzia, Lactobacillus, Streptococcus, and Akkermansia muciniphila (Caesar et al., 2015). In contrast, another study on rats reported an increase in Akkermansia in response to intake of a lardcontaining diet, while intake of a fish oil-containing diet was associated with a higher abundance of Desulfovibrio, Bilophila, Desulfovibrio, and Helicobacter (Li et al., 2017). The different results may relate to differences in study designs, e.g., different rodent species, sample handling, $16 \mathrm{~S}$ rRNA profiling, dietary fat amount and/or fat origin. 
Although lipids may modulate the gut microbiota, the identity of the factors in dietary fat important for this regulation has not been fully established. For example, it is not clear to which extent fatty acid composition, viscosity or $n-6 / n-3$ polyunsaturated fatty acid ratio impact on the gut microbiota. The gut microbiota regulates bile acid synthesis and modulates conjugation of secondary bile acids. Visa versa, bile acids modify the gut microbiota, for example by promoting the growth of bacteria using bile acids as a substrate or through antimicrobial effects (reviewed in Wahlstrom, Sayin, Marschall, \& Backhed, 2016). Due to the bi-directional relationship between the gut microbiota and bile acid metabolism, it is not clear to what extent dietary lipids impact on microbial composition directly, e.g., via acting as a substrate for bacterial metabolism, and/or via secondary metabolites such as changes in bile acid composition. Experiments interfering with bile acid synthesis or metabolism may, in combination with intake of various dietary lipids, shed light on direct effects of fatty acid on the gut microbiota. Another approach is to use systems such as an artificial gut.

Differences in intake of dietary fatty acids also affect temporal changes in the gut microbiota. A high-fat/high-sucrose diet may rapidly alter the composition of the gut microbiota in rodents (Collins et al., 2016). However, in our hands, cecal and colonic microbiota in mice did not change significantly during five weeks on a safflower based high-fat/high-sucrose diet (DanneskioldSamsoe et al., 2017). One explanation for this could be that only very few percentages of the ingested lipids reach the gut bacteria in the colon (Booth, Alldis, \& Read, 1961), due to their main absorption in the ileum part of the small intestine.

Contrasting the knowledge of complex carbohydrates, it is still unclear if and how lipids change the microbiota in the large intestine in humans. Further studies are needed to fully elucidate how different dietary lipids impact on the composition and functional capacity of the gut microbiota.

\section{EFFECT OF POLYPHENOLS ON MICROBIOTA}

Phenolic compounds are phytochemicals found in a huge variety of fruits and vegetables being secondary metabolites in plants. This class of compounds is characterized by the presence of various hydroxyl groups in aromatic rings and are divided into two main categories: flavonoids and non-flavonoids (Santhakumar; Battino; Alvarez-Suarez, 2018). Interest in phenolic compounds is related to their health beneficial effects which have been associated with anti-oxidant, antiinflammatory, cardioprotective, cancer preventive, and neuroprotective properties (Figure 1) (Selma; Espín; Tomás-Barberán, 2009). 
The intestinal microbiota is capable of metabolizing phenolic compounds making them potentially more biologically active than the primary compounds and more easily absorbed by the body (Selma; Espín; Tomás-Barberán, 2009). One such example was recently described by Theilmann et al., illustrating the capacity of Lactobacillus acidophilus for deglucosylation of dietary plant glycosides making the produced aglycones of the plant glycosides available for modification by other bacterial taxa or for direct use by the host. Polyphenols may also modulate the gut microbiota in a process termed the prebiotic-like effect (Tomás-Barberán; Selma; Espín, 2016). The classical prebiotic-like effect of polyphenols has been investigated in in vitro assays using human microbiota, and in preclinical and clinical studies with polyphenol-rich food.

Sun et al. (2018), evaluated the in vitro effect of green tea, oolong tea, and black tea on samples of the intestinal microbiota and concluded that the tea polyphenols significantly increased the abundance of Bifidobacterium, Lactobacillus spp. and Enterococcus spp. (Figure 1), and also enhanced SCFA production, while restraining the proliferation of the Bacteroides, Prevotella and Clostridium histolyticum groups. Moreover, Larrosa et al. (2009) studied the effect of resveratrol on the colon microbiota in a rat model of DSS-induced colitis and observed an increase in Lactobacilli and Bifidobacteria with a concurrent decrease in the abundance of E. coli and Enterobacteria.

Polyphenols can modulate the gut microbiota by promoting the growth of specific gut microbial species including Akkermansia spp., Faecalibacterium spp. and Roseburia spp. (Figure 1) that may provide beneficial health effects to the host (Reviewed in Espín et al., 2017; TomásBarberán et al., 2016). Akkermansia is a mucin-degrading bacterium that resides in the mucus layer, and its abundance is inversely correlated with body weight and with an improved metabolic profile (Everard et al., 2013). Faecalibacterium spp. and Roseburia spp. are among the most abundant butyrate-producing gut bacteria. Corroborating these results, Moreno-Indias et al. (2016) studied the effect of red wine polyphenols in obese patients with metabolic syndrome and concluded that polyphenols increased the number of butyrate-producing bacteria.

Due to the vast number of polyphenolic compounds, the high number of derived bioconversion products and their interaction with the gut microbiota, it has in general been difficult convincingly to link beneficial health effects to specific polyphenolic compounds. This situation has now been greatly improved by the development of Phenol Explorer Database Release 3.0 (Rothwell et al., 2013), which is an assembly of a large array of metabolite data obtained from analyses of urine and plasma samples collected after intake of polyphenolic compounds and coupled to health data. Broadly speaking, the many plant-derived polyphenolic products make up a vast variety of 
bioactive compounds reported to elicit positive effects with regard to anti-microbial, anti-oxidant, anti-inflammatory, anti-diabetic, and anti-cancer activities based on studies in ex vivo cell systems or results obtained after intake of phenolic-rich compounds (Scalbert, Manach, Morand, Remesy, \& Jimenez, 2005).

\section{FOOD-DERIVED MICROBIAL METABOLITES AFFECTING HEALTH AND DISEASE}

As illustrated above, several of the food-derived microbial degradation products/metabolites have been demonstrated to hold health beneficial properties via their effects on local and systemic inflammatory paths involved in different disease processes. Most studied effects relate to the SCFAs derived from gut bacterial fermentation of certain fibers, the tryptophan metabolites, resulting mainly from bacterial conversion of the dietary amino acid tryptophan, and the polyphenolic degradation products derived from bacterial metabolism of dietary phenolic compounds. Overall, these products are associated with favorable health-related phenotypes via modification of pro-inflammatory cues driving lifestyle-related, inflammation-mediated diseases, which will be addressed in more detail below.

The fiber-derived fermentation products including the SCFAs butyrate, propionate and acetate contribute to a variety of positive health effects both locally in the intestine and systemically. For example, in animal models of inflammatory bowel disease, where reduced levels of SCFAs in the feces associate with disease severity (Cazarin et al., 2015), and in humans, where lack of bacteria with potential for SCFA production is a signature of Crohn's disease patients (He et al., 2017). Butyrate has been shown to hold widely acting effects by inducing mucin synthesis, decreasing bacterial transport across the epithelium, and improving gut integrity by increasing tight junction assembly (Peng, Li, Green, Holzman, \& Lin, 2009). In general, SCFAs have been shown to act as histone deacetylase inhibitors and ligands for $G$ protein-coupled receptor 41 (GPR41), G proteincoupled receptor 43 (GPR43), (all SCFAs) and G protein- coupled receptor 109A (butyrate) locally in the gut resulting in suppression of pro-inflammatory cytokine secretion (Arpaia et al., 2013; Furusawa et al, 2013). Butyrate and propionate are also able to influence differentiation of naïve $\mathrm{T}$ cells into Tregs, the latter playing a vital role in controlling intestinal homeostasis (Arpaia et al., 2013; Smith et al., 2013).

Moreover, via its interaction with GPR109A, butyrate has been shown to mediate secretion of IL-18 via intestinal epithelial cells (Singh et al, 2014), which is reported to be involved in 
suppression of colonic inflammation (Elinav et al., 2011; Salcedo et al., 2010). It is important to note that GPR109A is also a receptor for niacin, wherefore dietary niacin may be able to mediate some of the GPR109A-related effects (Singh et al, 2014). GPR109A additionally triggers secretion of immunosuppressive IL-10 and class 1A aldehyde dehydrogenase (Aldh1A) from dendritic cells and macrophages of importance for intestinal homeostasis. Neutrophils, which are vital for removal of extracellular pathogenic microorganisms, also act under the influence of SCFAs, where GPR43 is reported to be involved in regulating neutrophilic activity (Sina et al., 2009). Moreover, propionate may play a role in relation to iron deficiency, which is a serious health problem that eventually may lead to reduced cognitive development, growth impairment, and inflammatory states. In this regard, propionate seems to enhance iron absorption in the proximal colon (Bougle et al., 2002).

The secretion of glucagon-like peptide-1 (GLP-1), which is an incretin hormone responsible for stimulating insulin release, has been linked with the levels of SCFAs in the gut (Lin et al., 2012; Yadav, Lee, Lloyd, Walter, \& Rane, 2013). Butyrate seems to most potently increase GLP-1 secretion, followed by propionate and lastly acetate. Several studies have shown that if GPR41 and GPR43 are both lacking, then GLP-1 secretion is reduced (Tolhurst et al., 2012; Yadav et al., 2013). Butyrate may moreover improve insulin sensitivity. In this regard, Gao et al. (2009) showed improved insulin sensitivity in mice fed butyrate at 5\% wt/wt for 16 weeks as part of a high-fat diet. A recent study by Zhao et al. (2018) has likewise demonstrated positive effects of expanding certain gut bacteria by a dietary fiber intervention in type 2 diabetic individuals, linked with GLP-1 secretion enhancement and HbAlc improvement. SCFAs also appear to play a role in relation to type 1 diabetes, as type 1 non-obese diabetic (NOD) mice supplemented with acetate and butyrate exhibited reduced incidence of diabetes by boosting local Treg function, suppressing numbers of autoreactive T cells, and by enhancing gut integrity (Marino et al., 2017).

SCFAs are also reported to mediate effects in organs distant from the gut. One seminal study by Trompette et al. (2014) illustrated how diet-induced changes of SCFA production in gut microbiota influence the lung immune system of relevance in asthma. Four groups of mice were fed with a readily fermentable fiber diet (pectin-rich), a poorly fermentable fiber diet (cellulose), a control diet (4\% fiber) or a low-fiber diet ( $<3 \%$ fiber). Intake of the low fiber diet resulted in an increase in IL-4, IL-5, IL-13, IL-17A, goblet cell hyperplasia, and increased mucus production in lung tissue, as well as in circulating total levels of $\operatorname{IgE}$ antibodies, all being phenotypic markers in asthma. Mice fed the pectin-rich diet showed the opposite results (Trompette et al., 2014). 
Trompette et al. (2014) further showed that mice treated with propionate increased the numbers of dendritic cells in the bone marrow, and these dendritic cells exhibited an impaired ability to activate Th2 effector cells in the lung, thus alleviating induced asthma symptoms.

Bacterial-derived tryptophan metabolites are also potent modifiers of host health. The amino acid tryptophan released from digestion of protein is converted to different tryptophan metabolites by the microbiota, resulting in an array of different tryptophan metabolites, such as indole, indole-3acetate, indole-3-aldehyde, and tryptamine with different ligand properties. Tryptophan metabolites have been shown to mediate their function via binding to the aryl hydrocarbon receptor (AhR) present in certain immune cell subsets, including all innate lymphoid cell (ILC) subtypes, monocytes, macrophages, and dendritic cells (www.immgen.org). The AhR is involved in regulation of insulin responsiveness, energy expenditure and specialization of a subtype of ILCs called ILC22, which plays a part in promoting gut barrier integrity (Figure 1) (Lee et al., 2011). Lack of tryptophan metabolites has been linked to inflammatory bowel disease (Lamas et al., 2016; Monteleone et al., 2011), weight changes ( $\mathrm{Lu}$ et al, 2015; Monteleone et al., 2011), and insulin resistance ( $\mathrm{Lu}$ et al., 2015; Wang et al., 2011). Activation of the AhR is known to regulate genes containing upstream XRE boxes, and to stimulate degradation of specific regulatory proteins via ubiquitination (Nguyen, Hanieh, Nakahama, \& Kishimoto, 2013). This results in a wide span of regulatory effects and powerful responses, in particular to regulation of genes related to cell specialization (Lamas et al., 2016; Monteleone et al., 2011; Veldhoen et al., 2008), insulin sensitivity (Lu et al., 2015; Roh et al., 2015; C. Wang et al., 2011), autoimmune responses (Uyttenhove \& Van Snick, 2006), and energy consumption (Lu et al., 2015; Monteleone et al., 2011). The amount and composition of microbial-derived tryptophan metabolites interacting with AhR might be of great importance in the causation chain from diet to health.

While it is well-documented that gut bacteria-derived metabolites from the amino acid tryptophan contribute to positive health effects, it seems that switching of gut bacteria towards production of the BCAAs may mediate negative health effects. Recent focus has been directed towards the possible adverse metabolic effects mediated via production of BCAA by specific gut bacteria, such as Prevotella copri and Bacteroides vulgatus, during certain high fat and low fiber conditions (Pedersen et al., 2016). Contrarily, BCAAs seem not to be produced by bacteria during high dietary fiber intake (Kovatcheva-Datchary et al., 2015), hence suggesting a role of the diet in bacterial BCAA production. The role of BCAAs in regulation of metabolism is complex and far 
from elucidated with several studies showing that increased diet-based intake of BCAAs protects against obesity and insulin resistance (Freudenberg, Petzke, \& Klaus, 2012, 2013; Newgard et al., 2009), whereas increased potential for BCAA synthesis in gut bacteria has been associated with insulin resistance (Pedersen et al., 2016). The adverse effects of BCAAs may be promoted when BCAAs are not used as constituents for the build-up of muscle proteins (non-exercising conditions), resulting in increased circulating levels that may interfere with insulin signaling. The possible continuous supply of BCAA to metabolic organs due to microbial production of BCAA is thus speculated to play a role in driving an insulin-resistant phenotype in inactive individuals with low fiber/ high fat dietary habits (Pedersen et al., 2016).

Concerning the polyphenolic compounds, the reciprocal interactions between gut microbiota and dietary phenolic compounds influence the bioavailability of the compounds and their effects on human health. As stated earlier, phenolic compounds that are not absorbed in the small intestine, fuel growth of colonic gut bacteria that in turn modify the bioavailability of the phenolic compounds (van Duynhoven et al., 2011). The bioavailability and health effects of polyphenols largely depend on their biotransformation by certain gut bacteria via specific microbial esterase, glucosidase, demethylation, dehydroxylation and decarboxylation activities (Possemiers, Bolca, Verstraete, \& Heyerick, 2011; Theilmann et al., 2017). Further interaction with the host metabolic system occurs via additional phenolic biotransformations, giving rise to hydroxylation of aromatic rings, O-methylation, O-demethylation, and conjugation of hydroxy groups to produce glucuronides and sulfates based polyphenolic products.

The anti-oxidant response by some polyphenolic compounds, especially flavonoids, seems to be mediated via activation of the transcription factor Nuclear factor (erythroid-derived 2)-like 2 (Nrf2), which is a regulator of various genes harboring the anti-oxidant response element (ARE) (Kumar, Kim, More, Kim, \& Choi, 2014). This effect may be partly mediated via interaction with a cytosolic form of the AhR (Miao, Hu, Scrivens, \& Batist, 2005). Different phenolic compounds, especially flavonoids and their metabolites, have been shown to agonistically regulate peroxisome proliferator-activated receptor gamma (PPAR $\gamma$ ) activation to exert effects on inflammatory transcription factors, leading to suppression of inflammation and modification of phenotypes related to metabolic diseases (Wang et al., 2014).

Many of the above-mentioned effects are based on cell culture studies with supraphysiological concentrations or studies in animal models. As also stated above, the field has 
struggled to identify effects of polyphenols in humans. However, a recent meta-analysis based on ten human intervention studies reported that different polyphenol-based interventions in humans were found to significantly reduce diastolic blood pressure and triglyceride levels (Marx et al., 2017), while inconclusive effects on systemic pro-inflammatory markers (CRP and IL-6) as well as oxidative stress markers, except for myeloperoxidase, were found. Based on this combined analysis, Marx and colleagues reported that there was little consistency in outcomes between human studies that measured the same outcome and/or used the same intervention (e.g., blood pressure), exemplifying the challenge in reproducing effects. Therefore, future studies are required to expand the currently limited evidence base on polyphenolic derived health effects in humans. A further consideration for future research is also to address the poor bioavailability of specific polyphenols, and the inter-individual differences in the gut microbiota, as individual differences in the gut microbiota may have a significant impact on the bioconversion of certain polyphenols (Manach et al., 2017). Addressing effects of dietary polyphenolic in human interventions may thereby require a more person-centric view.

\section{CONCLUDING REMARKS}

It is now generally accepted that health benefits from intake of plant-derived foods to a large extent are linked to changes in gut microbiota composition and production of bacterially-derived metabolites. At present, most focus has been directed towards SCFAs, tryptophan metabolites and polyphenolic compounds owing to their various positive effects on immune and metabolic cues of relevance in life-style associated diseases. However, due to limited insight into how to modify the gut microbiota composition and metabolic capacity by specific diets, we have a yet unexploited potential regarding the role of other metabolites. We also lack knowledge of the role of individual microorganisms, as well as communities, in relation to uptake and bioconversion of specific dietary compounds. It is therefore highly needed that we establish methods to study the role and metabolic capacity of single species and complex communities. This includes an understanding of interactive microbial networks in order to increase our knowledge on how to build robust health-promoting microbial communities that will adapt positively to personal dietary habits. Given the complexity of the vast number of mutual interactions between diet, microbiota, metabolic responses and the immune system, the next level of understanding depends on access to big comprehensive data sets, the development and implementation of machine learning algorithms, and the use of artificial intelligence-based approaches. Information from such comprehensive analyses would be a keystone 
in developing future approaches for prevention of lifestyle-associated diseases via personalized nutrition strategies.

\section{ACKNOWLEDGEMENTS}

HDFQB thanks São Paulo Research Foundation - FAPESP, for financial support (grant 042318/2017). All authors would like to thank the Innovation Fund Denmark (grant 5133-00011B), the Danish Ministry of Higher Education and Science (grant 5132-00101B) and São Paulo Research Foundation - FAPESP (grant 50333-1/2015) for support. MRMJ thanks CNPq (301108/2016-1) for support.

\section{AUTHOR CONTRIBUTIONS}

JLB drafted the first version of the introduction, CBBC the section on carbohydrates, RS and GMP the section on prebiotics, LM and KK the section on proteins, NBDS the section on lipids, HDFQB and MRMJ the section on polyphenols, and SB the section on host-microbial metabolite interactions and the concluding remarks. KK, CBBC, MRMJ, SB and NBDS made extensive restructuring and revisions of the manuscript.

Figure 1. Overview of interplay between food components, gut microbiota, metabolites and host health. Dietary nutrients are associated with changes in gut microbiota composition and activity. Bacterial activity results in the generation of secondary metabolites which again interact with gut microbiota and modulate host responses. Genera whose abundance (second column from the left) is modulated by selected dietary nutrients (first column from the left). Arrows indicate interaction between gut microbiota and metabolites. SCFA: short-chain fatty acid, branched-chain fatty acids (BCAA), Ahr: Aryl: aryl hydrocarbon receptor TMAO: trimethylamine oxide. 


\section{REFERENCES}

An, H. M., Park, S. Y., Lee, D. K., Kim, J. R., Cha, M. K., Lee, S. W., . . Ha, N. J. (2011). Antiobesity and lipid-lowering effects of Bifidobacterium spp. in high fat diet-induced obese rats. Lipids Health Dis, 10, 116.

Arpaia, N., Campbell, C., Fan, X., Dikiy, S., van der Veeken, J., deRoos, P., . . Rudensky, A. Y. (2013). Metabolites produced by commensal bacteria promote peripheral regulatory T-cell generation. Nature, 504(7480), 451-455.

Azcarate-Peril, M. A., Ritter, A. J., Savaiano, D., Monteagudo-Mera, A., Anderson, C., Magness, S. T., \& Klaenhammer, T. R. (2017). Impact of short-chain galactooligosaccharides on the gut microbiome of lactose-intolerant individuals. Proc Natl Acad Sci U S A, 114(3), E367-E375.

Beleli, C. A., Antonio, M. A., dos Santos, R., Pastore, G. M., \& Lomazi, E. A. (2015). Effect of 4'galactooligosaccharide on constipation symptoms. J Pediatr (Rio J), 91(6), 567-573.

Booth, C. C., Alldis, D., \& Read, A. E. (1961). Studies on the site of fat absorption: 2 Fat balances after resection of varying amounts of the small intestine in man. Gut, 2(2), 168-174.

Bougle, D., Vaghefi-Vaezzadeh, N., Roland, N., Bouvard, G., Arhan, P., Bureau, F., ... Maubois, J. L. (2002). Influence of short-chain fatty acids on iron absorption by proximal colon. Scand J Gastroenterol, 37(9), 1008-1011.

Caesar, R., Tremaroli, V., Kovatcheva-Datchary, P., Cani, P. D., \& Backhed, F. (2015). Crosstalk between Gut Microbiota and Dietary Lipids Aggravates WAT Inflammation through TLR Signaling. Cell Metab, 22(4), 658-668.

Carding, S., Verbeke, K., Vipond, D. T., Corfe, B. M., \& Owen, L. J. (2015). Dysbiosis of the gut microbiota in disease. Microb Ecol Health Dis, 26, 26191.

Cazarin, C. B. B., da Silva, J. K., Colomeu, T. C., Batista, Â. G., Meletti, L. M. M., Paschoal, J. A. R., . . Maróstica Júnior, M. R. (2015). Intake of Passiflora edulis leaf extract improves antioxidant and anti-inflammatory status in rats with 2,4,6-trinitrobenzenesulphonic acid induced colitis. Journal of Functional Foods, 17, 575-586.

Cazarin, C. B. B., da Silva, J. K., Colomeu, T. C., Batista, A. G., Meletti, L. M. M., Paschoal, J. A. R., . . Marostica, M. R. (2015). Intake of Passiflora edulis leaf extract improves antioxidant and anti-inflammatory status in rats with 2,4,6-trinitrobenzenesulphonic acid induced colitis. Journal of Functional Foods, 17, 575-586.

Cazarin, C. B. B., Rodriguez-Nogales, A., Algieri, F., Utrilla, M. P., Rodríguez-Cabezas, M. E., Garrido-Mesa, J., . . . Gálvez, J. (2016). Intestinal anti-inflammatory effects of Passiflora edulis peel in the dextran sodium sulphate model of mouse colitis. Journal of Functional Foods, 26, 565-576.

Chang, Y. Y., Chou, C. H., Chiu, C. H., Yang, K. T., Lin, Y. L., Weng, W. L., \& Chen, Y. C. (2011). Preventive effects of taurine on development of hepatic steatosis induced by a highfat/cholesterol dietary habit. J Agric Food Chem, 59(1), 450-457.

Chassard, C., \& Lacroix, C. (2013). Carbohydrates and the human gut microbiota. Curr Opin Clin Nutr Metab Care, 16(4), 453-460.

Cho, C. E., Taesuwan, S., Malysheva, O. V., Bender, E., Tulchinsky, N. F., Yan, J., . . Caudill, M. A. (2017). Trimethylamine-N-oxide (TMAO) response to animal source foods varies among healthy young men and is influenced by their gut microbiota composition: A randomized controlled trial. Molecular Nutrition \& Food Research, 61(1), 1600324.

Clark, R. I., \& Walker, D. W. (2018). Role of gut microbiota in aging-related health decline: insights from invertebrate models. Cell Mol Life Sci, 75(1), 93-101. 
Cockburn, D. W., \& Koropatkin, N. M. (2016). Polysaccharide Degradation by the Intestinal Microbiota and Its Influence on Human Health and Disease. J Mol Biol, 428(16), 32303252 .

Collins, K. H., Paul, H. A., Hart, D. A., Reimer, R. A., Smith, I. C., Rios, J. L., . . Herzog, W. (2016). A High-Fat High-Sucrose Diet Rapidly Alters Muscle Integrity, Inflammation and Gut Microbiota in Male Rats. Scientific Reports, 6, 37278.

Daguet, D., Pinheiro, I., Verhelst, A., Possemiers, S., \& Marzorati, M. (2016). Arabinogalactan and fructooligosaccharides improve the gut barrier function in distinct areas of the colon in the Simulator of the Human Intestinal Microbial Ecosystem. Journal of Functional Foods, 20, 369-379.

Danneskiold-Samsoe, N. B., Andersen, D., Radulescu, I. D., Normann-Hansen, A., Brejnrod, A., Kragh, M., ... Kristiansen, K. (2017). A safflower oil based high-fat/high-sucrose diet modulates the gut microbiota and liver phospholipid profiles associated with early glucose intolerance in the absence of tissue inflammation. Mol Nutr Food Res, 61(5).

De Filippis, F., Pellegrini, N., Vannini, L., Jeffery, I. B., La Storia, A., Laghi, L., . . Ercolini, D. (2015). High-level adherence to a Mediterranean diet beneficially impacts the gut microbiota and associated metabolome. Gut 65(11), 1812-1821.

De Filippo, C., Cavalieri, D., Di Paola, M., Ramazzotti, M., Poullet, J. B., Massart, S., ... Lionetti, P. (2010). Impact of diet in shaping gut microbiota revealed by a comparative study in children from Europe and rural Africa. Proc Natl Acad Sci U S A, 107(33), 14691-14696.

Devkota, S., Wang, Y., Musch, M. W., Leone, V., Fehlner-Peach, H., Nadimpalli, A., ... Chang, E. B. (2012). Dietary-fat-induced taurocholic acid promotes pathobiont expansion and colitis in Il10-/- mice. Nature, 487(7405), 104-108.

Dumas, M. E., Rothwell, A. R., Hoyles, L., Aranias, T., Chilloux, J., Calderari, S., ... Gauguier, D. (2017). Microbial-Host Co-metabolites Are Prodromal Markers Predicting Phenotypic Heterogeneity in Behavior, Obesity, and Impaired Glucose Tolerance. Cell Rep, 20(1), 136148.

Duncan, S. H., Belenguer, A., Holtrop, G., Johnstone, A. M., Flint, H. J., \& Lobley, G. E. (2007). Reduced dietary intake of carbohydrates by obese subjects results in decreased concentrations of butyrate and butyrate-producing bacteria in feces. Appl Environ Microbiol, 73(4), 1073-1078.

Eaton, S. B., Eaton, S. B., 3rd, Konner, M. J., \& Shostak, M. (1996). An evolutionary perspective enhances understanding of human nutritional requirements. J Nutr, 126(6), 1732-1740.

El Kaoutari, A., Armougom, F., Gordon, J. I., Raoult, D., \& Henrissat, B. (2013). The abundance and variety of carbohydrate-active enzymes in the human gut microbiota. Nature Reviews Microbiology, 11(7), 497-504.

Elinav, E., Strowig, T., Kau, A. L., Henao-Mejia, J., Thaiss, C. A., Booth, C. J., . . Flavell, R. A. (2011). NLRP6 inflammasome regulates colonic microbial ecology and risk for colitis. Cell, 145(5), 745-757.

Everard, A., Belzer, C., Geurts, L., Ouwerkerk, J. P., Druart, C., Bindels, L. B., . . Cani, P. D. (2013). Cross-talk between Akkermansia muciniphila and intestinal epithelium controls dietinduced obesity. Proc Natl Acad Sci U S A, 110(22), 9066-9071.

Freudenberg, A., Petzke, K. J., \& Klaus, S. (2012). Comparison of high-protein diets and leucine supplementation in the prevention of metabolic syndrome and related disorders in mice. Journal of Nutritional Biochemistry, 23(11), 1524-1530.

Freudenberg, A., Petzke, K. J., \& Klaus, S. (2013). Dietary L-leucine and L-alanine supplementation have similar acute effects in the prevention of high-fat diet-induced obesity. Amino Acids, 44(2), 519-528. 
Furusawa, Y., Obata, Y., Fukuda, S., Endo, T. A., Nakato, G., Takahashi, D., . . Ohno, H. (2013). Commensal microbe-derived butyrate induces the differentiation of colonic regulatory $\mathrm{T}$ cells. Nature, 504(7480), 446-450.

Gao, Z., Yin, J., Zhang, J., Ward, R. E., Martin, R. J., Lefevre, M., . . Ye, J. (2009). Butyrate improves insulin sensitivity and increases energy expenditure in mice. Diabetes, 58(7), 1509-1517.

Gibson, G. R., Hutkins, R., Sanders, M. E., Prescott, S. L., Reimer, R. A., Salminen, S. J., . . Reid, G. (2017). Expert consensus document: The International Scientific Association for Probiotics and Prebiotics (ISAPP) consensus statement on the definition and scope of prebiotics. Nat Rev Gastroenterol Hepatol, 14(8), 491-502.

Gibson, G. R., Scott, K., A Rastall, R., Tuohy, K., Hotchkiss, A., Dubert-Ferrandon, A., ... Buddington, R. (2010). Dietary prebiotics: Current status and new definition. Food Science and Technology Bulletin, 7(1), 1-19.

Graf, D., Di Cagno, R., Fak, F., Flint, H. J., Nyman, M., Saarela, M., \& Watzl, B. (2015). Contribution of diet to the composition of the human gut microbiota. Microb Ecol Health Dis, 26, 26164.

He, Q., Gao, Y., Jie, Z., Yu, X., Laursen, J. M., Xiao, L., .. . Jia, H. (2017). Two distinct metacommunities characterize the gut microbiota in Crohn's disease patients. Gigascience, 6(7), 1-11.

Holm, J. B., Ronnevik, A., Tastesen, H. S., Fjaere, E., Fauske, K. R., Liisberg, U., . . Liaset, B. (2016). Diet-induced obesity, energy metabolism and gut microbiota in C57BL/6J mice fed Western diets based on lean seafood or lean meat mixtures. J Nutr Biochem, 31, 127-136.

Holmes, A. J., Chew, Y. V., Colakoglu, F., Cliff, J. B., Klaassens, E., Read, M. N., . . Simpson, S. J. (2017). Diet-Microbiome Interactions in Health Are Controlled by Intestinal Nitrogen Source Constraints. Cell Metab, 25(1), 140-151.

Huang, E. Y., Leone, V. A., Devkota, S., Wang, Y., Brady, M. J., \& Chang, E. B. (2013). Composition of dietary fat source shapes gut microbiota architecture and alters host inflammatory mediators in mouse adipose tissue. JPEN J Parenter Enteral Nutr, 37(6), 746754.

Isokpehi, R. D., Simmons, S. S., Johnson, M. O., \& Payton, M. (2017). Genomic Evidence for Bacterial Determinants Influencing Obesity Development. Int J Environ Res Public Health, 14(4), 345.

Jie, Z., Xia, H., Zhong, S. L., Feng, Q., Li, S., Liang, S., . . Kristiansen, K. (2017). The gut microbiome in atherosclerotic cardiovascular disease. Nat Commun, 8(1), 845.

Koeth, R. A., Wang, Z., Levison, B. S., Buffa, J. A., Org, E., Sheehy, B. T., .. . Hazen, S. L. (2013). Intestinal microbiota metabolism of L-carnitine, a nutrient in red meat, promotes atherosclerosis. Nat Med, 19(5), 576-585.

Kovatcheva-Datchary, P., Nilsson, A., Akrami, R., Lee, Y. S., De Vadder, F., Arora, T., ... Backhed, F. (2015). Dietary Fiber-Induced Improvement in Glucose Metabolism Is Associated with Increased Abundance of Prevotella. Cell Metab, 22(6), 971-982.

Kumar, H., Kim, I. S., More, S. V., Kim, B. W., \& Choi, D. K. (2014). Natural product-derived pharmacological modulators of Nrf2/ARE pathway for chronic diseases. Nat Prod Rep, 31(1), 109-139.

Lamas, B., Richard, M. L., Leducq, V., Pham, H. P., Michel, M. L., Da Costa, G., ... Sokol, H. (2016). CARD9 impacts colitis by altering gut microbiota metabolism of tryptophan into aryl hydrocarbon receptor ligands. Nat Med, 22(6), 598-605.

Landfald, B., Valeur, J., Berstad, A., \& Raa, J. (2017). Microbial trimethylamine-N-oxide as a disease marker: something fishy? Microb Ecol Health Dis, 28(1), 1327309. 
Larrosa, M., Yanez-Gascon, M. J., Selma, M. V., Gonzalez-Sarrias, A., Toti, S., Ceron, J. J., . . . Espin, J. C. (2009). Effect of a low dose of dietary resveratrol on colon microbiota, inflammation and tissue damage in a DSS-induced colitis rat model. J Agric Food Chem, 57(6), 2211-2220.

Lee, J. S., Cella, M., McDonald, K. G., Garlanda, C., Kennedy, G. D., Nukaya, M., . . Colonna, M. (2011). AHR drives the development of gut ILC22 cells and postnatal lymphoid tissues via pathways dependent on and independent of Notch. Nat Immunol, 13(2), 144-151.

Leth, M. L., Ejby, M., Workman, C., Ewald, D. A., Pedersen, S. S., Sternberg, C., . . Abou Hachem, M. (2018). Differential bacterial capture and transport preferences facilitate cogrowth on dietary xylan in the human gut. Nat Microbiol, 3(5), 570-580.

Li, H., Zhu, Y., Zhao, F., Song, S., Li, Y., Xu, X., . . Li, C. (2017). Fish oil, lard and soybean oil differentially shape gut microbiota of middle-aged rats. Sci Rep, 7(1), 826.

Li, Z., Jin, H., Oh, S. Y., \& Ji, G. E. (2016). Anti-obese effects of two Lactobacilli and two Bifidobacteria on ICR mice fed on a high fat diet. Biochem Biophys Res Commun, 480(2), 222-227.

Liisberg, U., Myrmel, L. S., Fjaere, E., Ronnevik, A. K., Bjelland, S., Fauske, K. R., . . Madsen, L. (2016). The protein source determines the potential of high protein diets to attenuate obesity development in C57BL/6J mice. Adipocyte, 5(2), 196-211.

Lillefosse, H. H., Clausen, M. R., Yde, C. C., Ditlev, D. B., Zhang, X. M., Du, Z. Y., .. Liaset, B. (2014). Urinary Loss of Tricarboxylic Acid Cycle Intermediates As Revealed by Metabolomics Studies: An Underlying Mechanism to Reduce Lipid Accretion by Whey Protein Ingestion? Journal of Proteome Research, 13(5), 2560-2570.

Lin, H. V., Frassetto, A., Kowalik, E. J., Jr., Nawrocki, A. R., Lu, M. M., Kosinski, J. R., .. . Marsh, D. J. (2012). Butyrate and propionate protect against diet-induced obesity and regulate gut hormones via free fatty acid receptor 3-independent mechanisms. PLoS One, 7(4), e35240.

Lu, P., Yan, J., Liu, K., Garbacz, W. G., Wang, P., Xu, M., .. . Xie, W. (2015). Activation of aryl hydrocarbon receptor dissociates fatty liver from insulin resistance by inducing fibroblast growth factor 21. Hepatology, 61(6), 1908-1919.

Madsen, L., Myrmel, L. S., Fjaere, E., Liaset, B., \& Kristiansen, K. (2017). Links between Dietary Protein Sources, the Gut Microbiota, and Obesity. Frontiers in Physiology, 8, 1047.

Malik, V. S., Li, Y., Tobias, D. K., Pan, A., \& Hu, F. B. (2016). Dietary Protein Intake and Risk of Type 2 Diabetes in US Men and Women. Am J Epidemiol, 183(8), 715-728.

Manach, C., Milenkovic, D., Van de Wiele, T., Rodriguez-Mateos, A., de Roos, B., Garcia-Conesa, M. T., ... Morand, C. (2017). Addressing the inter-individual variation in response to consumption of plant food bioactives: Towards a better understanding of their role in healthy aging and cardiometabolic risk reduction. Mol Nutr Food Res, 61(6), 1600557.

Marchesi, J. R., Adams, D. H., Fava, F., Hermes, G. D., Hirschfield, G. M., Hold, G., ... Hart, A. (2016). The gut microbiota and host health: a new clinical frontier. Gut, 65(2), 330-339. Marino, E., Richards, J. L., McLeod, K. H., Stanley, D., Yap, Y. A., Knight, J., . . Mackay, C. R. (2017). Gut microbial metabolites limit the frequency of autoimmune T cells and protect against type 1 diabetes. Nat Immunol, 18(5), 552-562.

Marques, F. Z., Mackay, C. R., \& Kaye, D. M. (2018). Beyond gut feelings: how the gut microbiota regulates blood pressure. Nat Rev Cardiol, 15(1), 20-32.

Marx, W., Kelly, J., Marshall, S., Nakos, S., Campbell, K., \& Itsiopoulos, C. (2017). The Effect of Polyphenol-Rich Interventions on Cardiovascular Risk Factors in Haemodialysis: A Systematic Review and Meta-Analysis. Nutrients, 9(12), 345. 
McAllan, L., Speakman, J. R., Cryan, J. F., \& Nilaweera, K. N. (2015). Whey protein isolate decreases murine stomach weight and intestinal length and alters the expression of Wnt signalling-associated genes. British Journal of Nutrition, 113(2), 372-379.

Miao, W., Hu, L., Scrivens, P. J., \& Batist, G. (2005). Transcriptional regulation of NF-E2 p45related factor (NRF2) expression by the aryl hydrocarbon receptor-xenobiotic response element signaling pathway: direct cross-talk between phase I and II drug-metabolizing enzymes. J Biol Chem, 280(21), 20340-20348.

Monteleone, I., Rizzo, A., Sarra, M., Sica, G., Sileri, P., Biancone, L., . . Monteleone, G. (2011). Aryl hydrocarbon receptor-induced signals up-regulate IL-22 production and inhibit inflammation in the gastrointestinal tract. Gastroenterology, 141(1), 237-248, 248 e231.

Moreno-Indias, I., Sanchez-Alcoholado, L., Perez-Martinez, P., Andres-Lacueva, C., Cardona, F., Tinahones, F., \& Queipo-Ortuno, M. I. (2016). Red wine polyphenols modulate fecal microbiota and reduce markers of the metabolic syndrome in obese patients. Food Funct, 7(4), 1775-1787.

Muegge, B. D., Kuczynski, J., Knights, D., Clemente, J. C., Gonzalez, A., Fontana, L., ... Gordon, J. I. (2011). Diet drives convergence in gut microbiome functions across mammalian phylogeny and within humans. Science, 332(6032), 970-974.

Nakaya, Y., Minami, A., Harada, N., Sakamoto, S., Niwa, Y., \& Ohnaka, M. (2000). Taurine improves insulin sensitivity in the Otsuka Long-Evans Tokushima Fatty rat, a model of spontaneous type 2 diabetes. Am J Clin Nutr, 71(1), 54-58.

Nardelli, T. R., Ribeiro, R. A., Balbo, S. L., Vanzela, E. C., Carneiro, E. M., Boschero, A. C., \& Bonfleur, M. L. (2011). Taurine prevents fat deposition and ameliorates plasma lipid profile in monosodium glutamate-obese rats. Amino Acids, 41(4), 901-908.

Newgard, C. B., An, J., Bain, J. R., Muehlbauer, M. J., Stevens, R. D., Lien, L. F., . . Svetkey, L. P. (2009). A branched-chain amino acid-related metabolic signature that differentiates obese and lean humans and contributes to insulin resistance. Cell Metab, 9(4), 311-326.

Nguyen, N. T., Hanieh, H., Nakahama, T., \& Kishimoto, T. (2013). The roles of aryl hydrocarbon receptor in immune responses. Int Immunol, 25(6), 335-343.

O'Toole, P. W., \& Jeffery, I. B. (2018). Microbiome-health interactions in older people. Cell Mol Life Sci, 75(1), 119-128.

Park, D. Y., Ahn, Y. T., Park, S. H., Huh, C. S., Yoo, S. R., Yu, R., . . Choi, M. S. (2013). Supplementation of Lactobacillus curvatus HY7601 and Lactobacillus plantarum KY1032 in diet-induced obese mice is associated with gut microbial changes and reduction in obesity. PLoS One, 8(3), e59470.

Patterson, E., RM, O. D., Murphy, E. F., Wall, R., O, O. S., Nilaweera, K., . . Stanton, C. (2014). Impact of dietary fatty acids on metabolic activity and host intestinal microbiota composition in C57BL/6J mice. Br J Nutr, 111(11), 1905-1917.

Pedersen, H. K., Gudmundsdottir, V., Nielsen, H. B., Hyotylainen, T., Nielsen, T., Jensen, B. A., . . . Pedersen, O. (2016). Human gut microbes impact host serum metabolome and insulin sensitivity. Nature, 535(7612), 376-381.

Peng, L., Li, Z. R., Green, R. S., Holzman, I. R., \& Lin, J. (2009). Butyrate enhances the intestinal barrier by facilitating tight junction assembly via activation of AMP-activated protein kinase in Caco-2 cell monolayers. J Nutr, 139(9), 1619-1625.

Possemiers, S., Bolca, S., Verstraete, W., \& Heyerick, A. (2011). The intestinal microbiome: a separate organ inside the body with the metabolic potential to influence the bioactivity of botanicals. Fitoterapia, 82(1), 53-66.

Ramanan, D., \& Cadwell, K. (2016). Intrinsic Defense Mechanisms of the Intestinal Epithelium. Cell Host Microbe, 19(4), 434-441. Rampelli, S., Schnorr, S. L., Consolandi, C., Turroni, S., 
Severgnini, M., Peano, C., . . Candela, M. (2015). Metagenome Sequencing of the Hadza Hunter-Gatherer Gut Microbiota. Curr Biol, 25(13), 1682-1693.

Reichardt, N., Vollmer, M., Holtrop, G., Farquharson, F. M., Wefers, D., Bunzel, M., ... Louis, P. (2018). Specific substrate-driven changes in human faecal microbiota composition contrast with functional redundancy in short-chain fatty acid production. ISME J, 12(2), 610-622.

Robertson, R. C., Seira Oriach, C., Murphy, K., Moloney, G. M., Cryan, J. F., Dinan, T. G., ... Stanton, C. (2017). Deficiency of essential dietary n-3 PUFA disrupts the caecal microbiome and metabolome in mice. Br J Nutr, 118(11), 959-970.

Roca-Saavedra, P., Mendez-Vilabrille, V., Miranda, J. M., Nebot, C., Cardelle-Cobas, A., Franco, C. M., \& Cepeda, A. (2018). Food additives, contaminants and other minor components: effects on human gut microbiota-a review. J Physiol Biochem, 74(1), 69-83.

Roh, E., Kwak, S. H., Jung, H. S., Cho, Y. M., Pak, Y. K., Park, K. S., . . . Lee, H. K. (2015). Serum aryl hydrocarbon receptor ligand activity is associated with insulin resistance and resulting type 2 diabetes. Acta Diabetol, 52(3), 489-495.

Rooks, M. G., \& Garrett, W. S. (2016). Gut microbiota, metabolites and host immunity. Nat Rev Immunol, 16(6), 341-352.

Rosenbaum, M., Knight, R., \& Leibel, R. L. (2015). The gut microbiota in human energy homeostasis and obesity. Trends Endocrinol Metab, 26(9), 493-501.

Rothwell, J. A., Perez-Jimenez, J., Neveu, V., Medina-Remon, A., M'Hiri, N., Garcia-Lobato, P., . . . Scalbert, A. (2013). Phenol-Explorer 3.0: a major update of the Phenol-Explorer database to incorporate data on the effects of food processing on polyphenol content. Database (Oxford), 2013, bat070.

Roytio, H., Mokkala, K., Vahlberg, T., \& Laitinen, K. (2017). Dietary intake of fat and fibre according to reference values relates to higher gut microbiota richness in overweight pregnant women. Br J Nutr, 118(5), 343-352.

Salcedo, R., Worschech, A., Cardone, M., Jones, Y., Gyulai, Z., Dai, R. M., ... Trinchieri, G. (2010). MyD88-mediated signaling prevents development of adenocarcinomas of the colon: role of interleukin 18. J ExpMed, 207(8), 1625-1636.

Scalbert, A., Manach, C., Morand, C., Remesy, C., \& Jimenez, L. (2005). Dietary polyphenols and the prevention of diseases. Crit Rev Food Sci Nutr, 45(4), 287-306.

Shin, N. R., Lee, J. C., Lee, H. Y., Kim, M. S., Whon, T. W., Lee, M. S., \& Bae, J. W. (2014). An increase in the Akkermansia spp. population induced by metformin treatment improves glucose homeostasis in diet-induced obese mice. Gut, 63(5), 727-735.

Shoaf, K., Mulvey, G. L., Armstrong, G. D., \& Hutkins, R. W. (2006). Prebiotic galactooligosaccharides reduce adherence of enteropathogenic Escherichia coli to tissue culture cells. Infect Immun, 74(12), 6920-6928.

Sina, C., Gavrilova, O., Forster, M., Till, A., Derer, S., Hildebrand, F., . . Rosenstiel, P. (2009). G protein-coupled receptor 43 is essential for neutrophil recruitment during intestinal inflammation. J Immunol, 183(11), 7514-7522.

Singh, N., Gurav, A., Sivaprakasam, S., Brady, E., Padia, R., Shi, H., . . Ganapathy, V. (2014). Activation of Gpr109a, receptor for niacin and the commensal metabolite butyrate, suppresses colonic inflammation and carcinogenesis. Immunity, 40(1), 128-139.

Sircana, A., De Michieli, F., Parente, R., Framarin, L., Leone, N., Berrutti, M., .. . Musso, G. (2018). Gut Microbiota, Hypertension and Chronic kidney Disease: recent advances. Pharmacol Res.

Smith, P. M., Howitt, M. R., Panikov, N., Michaud, M., Gallini, C. A., Bohlooly, Y. M., ... Garrett, W. S. (2013). The microbial metabolites, short-chain fatty acids, regulate colonic Treg cell homeostasis. Science, 341(6145), 569-573. 
Sonnenburg, E. D., Smits, S. A., Tikhonov, M., Higginbottom, S. K., Wingreen, N. S., \& Sonnenburg, J. L. (2016). Diet-induced extinctions in the gut microbiota compound over generations. Nature, 529(7610), 56-64.

Spitze, A. R., Wong, D. L., Rogers, Q. R., \& Fascetti, A. J. (2003). Taurine concentrations in animal feed ingredients; cooking influences taurine content. J Anim Physiol Anim Nutr (Berl), 87(7-8), 251-262.

Sprong, R. C., Schonewille, A. J., \& van der Meer, R. (2010). Dietary cheese whey protein protects rats against mild dextran sulfate sodium-induced colitis: role of mucin and microbiota. $J$ Dairy Sci, 93(4), 1364-1371.

Sun, H., Chen, Y., Cheng, M., Zhang, X., Zheng, X., \& Zhang, Z. (2018). The modulatory effect of polyphenols from green tea, oolong tea and black tea on human intestinal microbiota in vitro. J Food Sci Technol, 55(1), 399-407.

Surana, N. K., \& Kasper, D. L. (2017). Moving beyond microbiome-wide associations to causal microbe identification. Nature, 552(7684), 244-247.

Tang, W. H., Wang, Z., Levison, B. S., Koeth, R. A., Britt, E. B., Fu, X., . . Hazen, S. L. (2013). Intestinal microbial metabolism of phosphatidylcholine and cardiovascular risk. $N$ Engl J Med, 368(17), 1575-1584.

Theilmann, M. C., Goh, Y. J., Nielsen, K. F., Klaenhammer, T. R., Barrangou, R., \& Abou Hachem, M. (2017). Lactobacillus acidophilus Metabolizes Dietary Plant Glucosides and Externalizes Their Bioactive Phytochemicals. MBio, 8(6).

Tolhurst, G., Heffron, H., Lam, Y. S., Parker, H. E., Habib, A. M., Diakogiannaki, E., ... Gribble, F. M. (2012). Short-chain fatty acids stimulate glucagon-like peptide-1 secretion via the Gprotein-coupled receptor FFAR2. Diabetes, 61(2), 364-371.

Torre-Villalvazo, I., Tovar, A. R., Ramos-Barragan, V. E., Cerbon-Cervantes, M. A., \& Torres, N. (2008). Soy protein ameliorates metabolic abnormalities in liver and adipose tissue of rats fed a high fat diet. J Nutr, 138(3), 462-468.

Tranberg, B., Madsen, A. N., Hansen, A. K., \& Hellgren, L. I. (2015). Whey-reduced weight gain is associated with a temporary growth reduction in young mice fed a high-fat diet. Journal of Nutritional Biochemistry, 26(1), 9-15.

Trompette, A., Gollwitzer, E. S., Yadava, K., Sichelstiel, A. K., Sprenger, N., Ngom-Bru, C., .. . Marsland, B. J. (2014). Gut microbiota metabolism of dietary fiber influences allergic airway disease and hematopoies is. Nat Med, 20(2), 159-166.

Uyttenhove, C., \& Van Snick, J. (2006). Development of an anti-IL-17A auto-vaccine that prevents experimental auto-immune encephalomyelitis. Eur J Immunol, 36(11), 2868-2874.

van Duynhoven, J., Vaughan, E. E., Jacobs, D. M., Kemperman, R. A., van Velzen, E. J., Gross, G., ... Van de Wiele, T. (2011). Metabolic fate of polyphenols in the human superorganism. Proc Natl Acad Sci U S A, 108 Suppl 1, 4531-4538.

Vandenplas, Y., Zakharova, I., \& Dmitrieva, Y. (2015). Oligosaccharides in infant formula: more evidence to validate the role of prebiotics. Br J Nutr, 113(9), 1339-1344.

Veldhoen, M., Hirota, K., Westendorf, A. M., Buer, J., Dumoutier, L., Renauld, J. C., \& Stockinger, B. (2008). The aryl hydrocarbon receptor links TH17-cell-mediated autoimmunity to environmental toxins. Nature, 453(7191), 106-109.

Ventura, M., O'Toole, P. W., de Vos, W. M., \& van Sinderen, D. (2018). Selected aspects of the human gut microbiota. Cell Mol Life Sci, 75(1), 81-82.

Viguiliouk, E., Stewart, S. E., Jayalath, V. H., Ng, A. P., Mirrahimi, A., de Souza, R. J., .. . Sievenpiper, J. L. (2015). Effect of Replacing Animal Protein with Plant Protein on Glycemic Control in Diabetes: A Systematic Review and Meta-Analysis of Randomized Controlled Trials. Nutrients, 7(12), 9804-9824. 
Wahlstrom, A., Sayin, S. I., Marschall, H. U., \& Backhed, F. (2016). Intestinal Crosstalk between Bile Acids and Microbiota and Its Impact on Host Metabolism. Cell Metab, 24(1), 41-50.

Wang, C., Xu, C. X., Krager, S. L., Bottum, K. M., Liao, D. F., \& Tischkau, S. A. (2011). Aryl hydrocarbon receptor deficiency enhances insulin sensitivity and reduces PPAR-alpha pathway activity in mice. Environ Health Perspect, 119(12), 1739-1744.

Wang, J., Tang, H., Zhang, C., Zhao, Y., Derrien, M., Rocher, E., . . Shen, J. (2015). Modulation of gut microbiota during probiotic-mediated attenuation of metabolic syndrome in high fat diet-fed mice. ISME J, 9(1), 1-15.

Wang, L., Waltenberger, B., Pferschy-Wenzig, E. M., Blunder, M., Liu, X., Malainer, C., ... Atanasov, A. G. (2014). Natural product agonists of peroxisome proliferator-activated receptor gamma (PPARgamma): a review. Biochem Pharmacol, 92(1), 73-89.

Winer, D. A., Luck, H., Tsai, S., \& Winer, S. (2016). The Intestinal Immune System in Obesity and Insulin Resistance. Cell Metab, 23(3), 413-426. Wu, G. D., Chen, J., Hoffmann, C., Bittinger, K., Chen, Y. Y., Keilbaugh, S. A., ... Lewis, J. D. (2011). Linking Long-Term Dietary Patterns with Gut Microbial Enterotypes. Science, 334(6052), 105-108.

Wu, R. Y., Abdullah, M., Maattanen, P., Pilar, A. V. C., Scruten, E., Johnson-Henry, K. C., . . . Sherman, P. M. (2017). Protein kinase C delta signaling is required for dietary prebioticinduced strengthening of intestinal epithelial barrier function. Scientific Reports, 7, 40820.

Xiao, L., Sonne, S. B., Feng, Q., Chen, N., Xia, Z. K., Li, X. P., . . Kristiansen, K. (2017). High-fat feeding rather than obesity drives taxonomical and functional changes in the gut microbiota in mice. Microbiome, 5, 43.

Yadav, H., Lee, J. H., Lloyd, J., Walter, P., \& Rane, S. G. (2013). Beneficial metabolic effects of a probiotic via butyrate-induced GLP-1 hormone secretion. J Biol Chem, 288(35), 2508825097.

Yang, Z., Huang, S., Zou, D., Dong, D., He, X., Liu, N., ... Huang, L. (2016). Metabolic shifts and structural changes in the gut microbiota upon branched-chain amino acid supplementation in middle-aged mice. Amino Acids, 48(12), 2731-2745.

Yoo, S. R., Kim, Y. J., Park, D. Y., Jung, U. J., Jeon, S. M., Ahn, Y. T., . . Choi, M. S. (2013). Probiotics L. plantarum and L. curvatus in Combination Alter Hepatic Lipid Metabolism and Suppress Diet-Induced Obesity. Obesity, 21(12), 2571-2578.

Yu, H., Guo, Z., Shen, S., \& Shan, W. (2016). Effects of taurine on gut microbio ta and metabolism in mice. Amino Acids, 48(7), 1601-1617.

Yu, H. N., Zhu, J., Pan, W. S., Shen, S. R., Shan, W. G., \& Das, U. N. (2014). Effects of fish oil with a high content of n-3 polyunsaturated fatty acids on mouse gut microbiota. Arch Med Res, 45(3), 195-202.

Zhao, L. P., Zhang, F., Ding, X. Y., Wu, G. J., Lam, Y. Y., Wang, X. J., . . Zhang, C. H. (2018). Gut bacteria selectively promoted by dietary fibers alleviate type 2 diabetes. Science, 359(6380), 1151-1156.

Zhu, Y., Shi, X., Lin, X., Ye, K., Xu, X., Li, C., \& Zhou, G. (2017). Beef, Chicken, and Soy Proteins in Diets Induce Different Gut Microbiota and Metabolites in Rats. Front Microbiol, 8, 1395.Zhu, Y. Y., Lin, X. S., Zhao, F., Shi, X. B., Li, H., Li, Y. Q., . . Zhou, G. H. (2015). Meat, dairy and plant proteins alter bacterial composition of rat gut bacteria. Scientific Reports, 5, 15220. 


\section{Highlights}

- An overview of how different food components drive changes in the gut microbiota

- Description of the reciprocal interactions between diet, gut microbiota and host

- Review of how food components may influence and determine human health

- Future directions to improve understanding of complexnetworks between diet, gut microbiota and health outcomes 


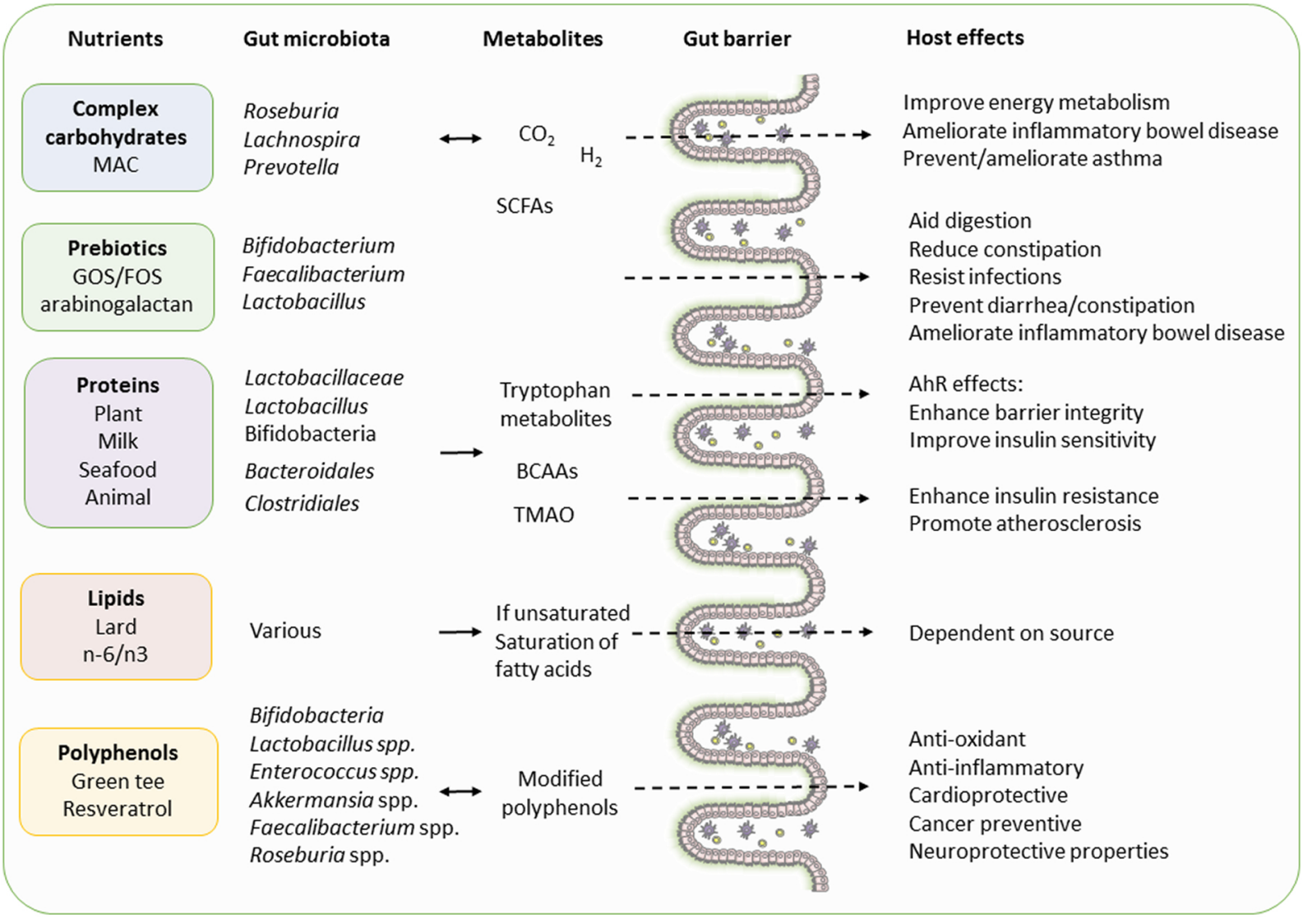

